\title{
Anti-Diabetic Activity of Methanolic Extract of Grape Seeds in Alloxan Induced Diabetic Rats
}

\author{
Maraia F Elmhdwi ${ }^{1 *}$, Naema M Saed Elaali ${ }^{1}$, Nura N Mohamed ${ }^{2}$, Mona A Muktar ${ }^{3}$ and Negia B buzgeia ${ }^{4}$ \\ ${ }^{1}$ Department of Chemistry, Faculty of Science, Benghazi University, Libya \\ ${ }^{2}$ Department of Medical biochemistry, Faculty of medicine, Benghazi University, Libya \\ ${ }^{3}$ Department of Chemistry, Faculty of Science, Ajdabiya University, Libya \\ ${ }^{4}$ Department of Medical biochemistry, Faculty of Pharmacy, Benghazi University, Libya
}

Submission: May 03, 2017; Published: May 24, 2017

"Corresponding author : Maraia F Elmhdwi, Department of Chemistry, Faculty of Science, Benghazi University, Libya,

Email: faragmaria20@gmail.com

\begin{abstract}
The present study was done to evaluate the anti-diabetic activity of methenolic extract of Grape Seeds (MEGS) in Alloxan induced diabetic rats. Diabetes was induced in Albino rats by administration of single doses of Alloxan monohydrate $(120 \mathrm{mg} / \mathrm{kg}$, I.P.).The (MEGS) at a dose of $50 \mathrm{mg} / \mathrm{kg}$ orally was administered as single dose per day to diabetes induced rats for period of 21 days. Acute toxity studies revealed the nontoxic nature of (MEGS), there were no lethality or toxic reactions found at any of the doses selected until the end of the study period. The effect of (MEGS) on blood glucose, serum lipid profile (Cholesterol, triglycerides, Phospholipids, very-low density lipoprotein (VLDL), Lowdensity lipoprotein (LDL), and high-density lipoprotein (HDL)), serum enzymes (serum glutamate oxaloacetate transaminases (SGOT), serum glutamate pyruvate transaminases (SGPT), alkaline phosphatases (ALP)), total protein were measured in the diabetic rats. The MEMM showed significant $(\mathrm{p}<0.01)$ reduction of blood glucose, lipid profile except HDL, and serum enzymes activity but significantly $(\mathrm{p}<0.01)$ increasedTotal protein in diabetic rats.
\end{abstract}

Keywords: Anti- diabetic activity; Grape seeds; Alloxan

\section{Introduction}

Diabetes mellitus (DM) is a metabolic disorder characterized by hyperglycemia resulting from defects in insulin secretion, insulin action or both [1]. The risk of diabetic complications includes many particularly cardiovascular diseases (CVD), peripheral vascular disease (PVD) [2]. Complications such as coronary artery disease (CAD), stroke, neuropathy, renal failure, retinopathy amputations, and blindness etc are known to be associated with DM [3]. More than 400 species of plants have been reported to display hypoglycemic effects, but only a few of them have been investigated. There are only a few reports on the effects of this plant in the literature and some of them presenting contradictory or unsuccessful results. Presently there are different groups of oral hypoglycemic agents for clinical use, having characteristic profiles of side effects [4]. Management of diabetes without any side effects is still a challenge to the medical system. This leads to increasing demand for natural products with anti-diabetic activity having fewer side effects. Type- 1 diabetes is an autoimmune disease. The most common form of diabetes is type- 2 diabetes. About 90 to $95 \%$ of people with diabetes have type-2. Non insulin dependent diabetes mellitus usually occurs after the age of forty [5]. This form of diabetes is associated with older age, obesity, family history of diabetes, previous history of gestational diabetes, physical inactivity and ethnicity. About $80 \%$ of people with type 2 diabetes are overweight. The facilitated diffusion of glucose into cells along a downhill gradient is ensured by glucose phosphorylation. This enzymatic reaction, the conversion of glucose to glucose6-phosphate (G-6-P), is accomplished by one of a family of hexokinases. The four hexokinases (I through IV) are distributed differently in tissues, and two are regulated by insulin. Hexokinase IV, a 50,000-dalton enzyme more commonly known as glucokinase, is found in association with GLUT2 in liver and pancreatic b cells. There is one glucokinase gene, but different first exons and promoters are employed in the two tissues [6]. 
The liver glucokinase gene is regulated by insulin. Hexokinase II is regulated transcriptionally by insulin.

Grape (Vitisvinifera) is one of the world's largest fruit crops and grape seeds are a complex matrix containing approximately $40 \%$ fiber, $16 \%$ oil, $11 \%$ proteins, and $7 \%$ complex phenols including tannins, in addition to sugars, mineral salts, etc. Proanthocyanidins of grape seeds are a group of polyphenolic bio flavonoids, which are known to possess broad pharmacological activities and therapeutic potentials [7]. Proanthocyanidins, the major polyphenols found in red wine and grape seeds, have been reported to show cardioprotective effects against ischemic reperfusion injury [8]. In addition, grape seeds are rich sources of monomeric phenolic compounds, such as (+)-catechins, (-)-epicatechin, (-)-epicatechin-3-o-gallate, and dimeric, trimeric and tetramericprocyanidins, which have antimutagenic and antiviral effects [9]. Recognition of such health benefits of catechins and procyanidins has facilitated the use of grape seeds extract as a dietary supplement. The objective of this research was to elucidate the relationship between heating and physical conditions of grape seeds on the antioxidant activity of grape seeds extract (GSE).This study was aimed to measurement the anti-diabetic activity in grape seeds with emphasize to its mechanism of action.

\section{Materials and Methods}

\section{Plant material}

The Grape was purchased from super market in Benghazi, Libya summer during 2016.

\section{Preparation of extract}

The Grape Seeds was extracted with methanol by a soxhlet apparatus for one week. The extract was concentrated to $1 / 4^{\text {th }}$ of its original volume by evaporation at room temperature. Each time before extracting with the next solvent, the residue was air dried thoroughly to remove the solvent used.

\section{Preliminary phytochemical analysis}

Plant active constituents responsible for anti-diabetic properties were isolated by thin layer chromatography (TLC). Acid hydrolysis was carried out on vaccum dried concentrated methanol extract of Grape Seeds to liberate a glycones, if any glycosides were present. The concentrates were spotted on activated TLC plates of silica gel. The plates were $(10 \times 10 \mathrm{~cm})$ developed with solvent system ethyl acetate, formic acid and water (85: 10: $15 \mathrm{v} / \mathrm{v}$ ) to elute flavonoides. The developed plates were air dried and detected by dip in solution of liquid paraffin and nhexane (1:2) and examine fluorescent spot under UV. [10].

An another plates were developed with solvent system concentrated HCL, acetic acid and water (3: 30: 10v/v) to elute coumarins. The developed plates were air dried and detected by UV.Light [11]. Retardation factor (Rf) values were calculated.

\section{Test for alkaloids}

Small portion of solvent free chloroform, ethanol and water extract with few drops of dilute $\mathrm{HCI}$ and filter. Using the following reagents carried out the test foralkaloids. Dragendroff's Test: A drop of various extracts was spotted on a small piece of pre coated TLC plate and the plate was sprayed with modified Dragendroff's reagent. (Orange coloration of the spot indicated presence of alkaloids).Hager's test: The extract was treated with a few $\mathrm{ml}$ of Hager's reagent (yellow precipitate indicated the presence of alkaloids). Wagner's test: The extracts were treated with few ml of Wagner's reagent (reddish brown Precipitate indicated the presence of alkaloids).

\section{Test for saponins}

The following tests for saponins were carried out: Foam Test: Dilute $1 \mathrm{ml}$ of extracts separately with distilled water to $20 \mathrm{ml}$ and shake with Graduated cylinder for 15 minutes. $1 \mathrm{~cm}$ layer foam indicated the presence of saponins. Hemolysis Test: Saponins produces hemolysis of red blood cells

\section{Test for glycosides}

Legal's Test: Dissolve the extract ( $0.1 \mathrm{gm})$ in pyridine $(2 \mathrm{ml})$ add sodiumnitroprusside solution $(2 \mathrm{ml})$ and make alkaline with sodium hydroxide solution (pink to red color solution indicated the presence of glycosides)

\section{Test for carbohydrates}

Molisch's test: Dissolve small quantity (300 mg) of alcoholic and aqueous Molisch test (Formation of reddish brown ring indicated presence of carbohydrate).

Fehling's test: Dissolve a small portion of extract in water and treat with Fehling's solution. (Brown colour indicated the presence of carbohydrate).

\section{Test for phenolic compounds and tannins}

Braemer's Test: To a $2-3 \mathrm{ml}$ of extracts, $10 \%$ alcoholic ferric chloride solution was added. (Dark blue orgreenish grey coloration of the solution indicated the presence of tannins).

\section{Test for proteins and amino acids}

Ninhydrin Test: Dissolve a small quantity of extracts in a few $\mathrm{ml}$ of water and subjected to ninhydrin. (Bluecoloration indicated the presence of amino acids).

\section{Tests for flavonoids}

Shinoda test: To $2-3 \mathrm{ml}$ of extracts, a piece of magnesium ribbon and $\mathrm{l} \mathrm{ml}$ of concentrated hydrochloric acid was added. (Pink red or red coloration of the solution indicated the presence off lavonoids).

Lead acetate Test: To $5 \mathrm{ml}$ of extract solution adds $\mathrm{lml}$ of lead acetate solution. (Flocculent whiteprecipitate indicated the presence of flavonoids).

\section{Test for Steroids/Terpenoids}

Libermann -burchard Test: To $1 \mathrm{ml}$ of extracts of drug $\mathrm{l}$ $\mathrm{ml}$ of chloroform, 2-3ml of acetic anhydride and 1 to 2 drops of concentrated sulphuric acid were added. (Dark green coloration of the solution indicated the presence of steroids and dark pink or red coloration of the solution indicated the presence of terpenoids). 


\section{Test for Fixed Oils and Fats}

Press small quantities of petroleum ether extract separately between two filter papers. Oil stains on the paper indicated the presence of fixed oils.

\section{Animals}

Male albino rats of Wistar strain weighing about $150-200 \mathrm{~g}$ were used for the study. The animal house was well ventilated and animals had $15-20 \pm 2{ }^{\circ} \mathrm{C}$. The animals were housed in large spacious hygienic cages during the course of the experimental period. The animals were fed with rat pellets feed supplied by M/s Hindustan Lever Limited, Bangalore, India and filtered water ad libitum. Animals described as fasted were deprived of food for $\geq 16 \mathrm{hr}$ but allowed free access to water. The place where the experiments were conducted was kept very hygienic by cleaning with antiseptic solution, as the diabetic animals are susceptible to infections [12].

\section{Evaluation of Anti-Diabetic Activity Experimental Grouping of Animals}

The experimental rats were divided into five groups of five animals in each group. The animals were fasted overnight before the experimental schedule began but allowed free access to tap water. Group I: The rats received $5 \%$ of carboxymethyl cellulose (CMC). These animals serve as healthy controls. Group II: The rats were made diabetic by an intraperitonial injection of Single dose of $(120 \mathrm{mg} / \mathrm{kg}$ body weight) alloxan monohydrate in normal saline. Group III: The methanolic extract of Grape seeds at a dose of $50 \mathrm{mg} / \mathrm{kg}$ body weight to the normal served as experimental control. Group IV: Only the methanolic extract of Grape seeds was given orally at a dose of $50 \mathrm{mg} / \mathrm{kg}$ body weight to the untreated animals served as a group. Group V: The diabetic rats were treated with $5 \mathrm{mg} / \mathrm{kg}$ of glibenclamide as standard drug.

\section{Induction of diabetes}

Alloxan monohydrate induced diabetes mellitus was induced in the normoglycaemic male albino rats. Animals were allowed to fast $24 \mathrm{hr}$ and were injected intraperitonially with freshly prepared alloxan monohydrate in sterile24hr of alloxanisation and it animals. The animals were maintained in the diabeticstate over a period of 21 days. Rats showing fasting blood glucose levels $(>250 \mathrm{mg} / \mathrm{dl})$ were selected for the study. Mortality rate of the animals were nil.

\section{Collection of blood sample}

A small amount of blood without sacrificing the animals was collected from the tail vein by snipping off the tip of the tail.

\section{Determination of blood glucose}

The blood from the tail vein was used to determine the glucose level. As bleeding starts, the animals were held close to the Pulsatum blood glucose test strip and allowed the drop to fall on the strip. The Pulsatum Glucometer was switched on and the test was allowed to react with the blood. After few seconds the blood glucose level was displayed on the screen. Table $1 \& 2$

Table 1: Presence of different plant constituents in various solvent extract.

\begin{tabular}{|c|c|c|c|c|}
\hline \multirow{2}{*}{$\begin{array}{c}\text { Grape Seeds } \\
\text { Constituents }\end{array}$} & $\begin{array}{c}\text { Petroleum } \\
\text { Ether }\end{array}$ & Chloroform & Methanol & Aqueous \\
\cline { 2 - 5 } & + & + & - & - \\
\hline Steroides & - & - & + & - \\
\hline Flavonoides & - & + & + & + \\
\hline Alkaloides & - & - & + & + \\
\hline Carohydrades & - & - & + & - \\
\hline Proteins & - & - & + & + \\
\hline Tannins & - & + & + & + \\
\hline Glycosides & - & - & - & + \\
\hline Saponins & - & - & - & - \\
\hline Triterpenes & + & - & - & + \\
\hline Fixed Oil & - & - & + & + \\
\hline Coumarines & - & - & + & + \\
\hline
\end{tabular}

Table 2: Effect of methanolic extract of Grape seeds (MEGS) on serum glucoseand total protein of control and experimental rats.

\begin{tabular}{|c|c|c|c|}
\hline Groups of Animals & Cholesterol (mg/dl) & Triglyceride (mg/dl) & Phospholipids(mg/dl) \\
\hline Normal control $(0.5 \% \mathrm{w} / \mathrm{v} \mathrm{CMC)}$ & $179.53 \pm 0.04$ & $211.18 \pm 0.54$ & $8.32 \pm 0.13$ \\
\hline Alloxan control $(120 \mathrm{mg} / \mathrm{kg})$ & $263.24 \pm 0.18^{* *}$ & $309 \pm 1.82^{* *}$ & $12.11 \pm 0.21^{* *}$ \\
\hline Alloxan+MEGS $(50 \mathrm{mg} / \mathrm{kg})$ & $209.05 \pm 1.11^{* *}$ & $280.63 \pm 1.14^{* *}$ & $9.88 \pm 0.04^{* *}$ \\
\hline MEGS $(50 \mathrm{mg} / \mathrm{kg})$ & $153.28 \pm 0.45^{*}$ & $221 \pm 0.65 \dagger$ & $8.45 \pm 0.12 \dagger$ \\
\hline Alloxan+Glibenclamide(5mg/kg) & $175.22 \pm 0.31^{* *}$ & $244.09 \pm 0.21^{* *}$ & $9.24 \pm 0.07^{* *}$ \\
\hline
\end{tabular}

The total protein content was significantly $(\mathrm{p}<0.01)$ decreased when compared to the normal control indiabetic rats and the level was restored to nearly normal after the treatment. There was no significant difference between normal control and rats only treated with extract.

The level of lipid profiles in normal control, diabetic control and experimental rats was depicted in table no.3 and 4 . In alloxan induced diabetic rats, there was a significant $(\mathrm{p}<0.01)$ increase of cholesterol, triglycerides, phospholipids, LDL and VLDL cholesterol and significant decrease in HDL cholesterol in serum compared to normal control. The plant extract used in the experimental study significantly $(\mathrm{p}<0.01)$ decrease the level of cholesterol, triglycerides, phospholipids, LDL and VLDL cholesterol and increase the level of HDL cholesterol. 


\section{Agricultural Research \& Technology: Open Access Journal}

Table 3: Effect of methanolic extract of Grape seeds (MEGS) on serum cholesterol, triglycerides, phospholipids, of control and experimental rats.

\begin{tabular}{|c|c|c|c|}
\hline Groups of Animals & Cholesterol (mg/dl) & Triglyceride (mg/dl) & Phospholipids(mg/dl) \\
\hline Normal control (0.5 \%w/v CMC) & $179.53 \pm 0.04$ & $211.18 \pm 0.54$ & $8.32 \pm 0.13$ \\
\hline Alloxan control (120mg/kg) & $263.24 \pm 0.18^{* *}$ & $309 \pm 1.82^{* *}$ & $12.11 \pm 0.21^{* *}$ \\
\hline Alloxan+MEGS (50mg/kg) & $209.05 \pm 1.11^{* *}$ & $280.63 \pm 1.14^{* *}$ & $9.88 \pm 0.04^{* *}$ \\
\hline MEGS (50mg/kg) & $153.28 \pm 0.45^{*}$ & $221 \pm 0.65 \dagger$ & $8.45 \pm 0.12 \dagger$ \\
\hline Alloxan+Glibenclamide(5mg/kg) & $175.22 \pm 0.31^{* *}$ & $244.09 \pm 0.21^{* *}$ & $9.24 \pm 0.07^{* *}$ \\
\hline
\end{tabular}

Table 4: Effect of methanolic extract of Grape seeds (MEGS) on serum HDL,LDL and VLDL of control and experimental rats.

\begin{tabular}{|c|c|c|c|}
\hline Groups of Animals & HDL (mg/dl) & LDL (mg/dl) & VLDL (mg/dl) \\
\hline $\begin{array}{c}\text { Normal control (0.5 \% } \\
\text { w/v CMC) }\end{array}$ & $88.12 \pm 0.23$ & $72.63 \pm 1.34$ & $41.32 \pm 1.00$ \\
\hline $\begin{array}{c}\text { Alloxan control } \\
(120 \mathrm{mg} / \mathrm{kg})\end{array}$ & $62.13 \pm 0.94^{* *}$ & $132.15 \pm 5.53^{* *}$ & $71.02 \pm 0.83^{* *}$ \\
\hline $\begin{array}{c}\text { Alloxan+MEGS (50mg/ } \\
\mathrm{kg})\end{array}$ & $73.12 \pm 0.36^{* *}$ & $97.01 \pm 1.60^{* *}$ & $62.92 \pm 0.26^{* *}$ \\
\hline MEGS (50mg/kg) & $78.15 \pm 0.60 \dagger$ & $83.07 \pm 0.90 \dagger$ & $39.54 \pm 0.11^{*}$ \\
\hline $\begin{array}{c}\text { Alloxan+Glibenclamide } \\
\text { (5mg/kg) }\end{array}$ & $78.08 \pm 0.49^{* *}$ & $88.95 \pm 0.11^{* *}$ & $53.21 \pm 1.39^{* *}$ \\
\hline
\end{tabular}

Data represents mean \pm S.D. $(n=5) .,{ }^{*} p<0.05$ Significant as compared to Alloxan control., ${ }^{* *} p<0.01$ Significantas compared to Alloxan control., ${ }^{* * *} p<0.001$ Significant as compared to Alloxan control., $\dagger$ : non significant compared to normal control.

This indicated the MEGS had favorable effect on lipid metabolism of diabetic rats. Diabetes Mellitus is a multifactorial disease, which is charecterised by hyperglycemia and lipoprotein abnormalities [13]. Glucose deprivation in diabetic condition increased the fat metabolism to supply energy to cells. The methanolic Grape seeds extract treated rats has restored both glucose and fat metabolism. Derangement of glucose, fat and protein metabolism during diabetes, results into the development of hyperlipidemia. [14-16] significant lowering of total cholesterol and rise in HDL cholesterol and rise in HDL cholesterol is a very desirable biochemical state for the prevention of atherosclerosis and is chemic conditions [17].

Table no. 4, depicts the activity of ALP, SGOT, SGPT, Alkaline phosphate, Serum Glutamase Oxalo acetate Transaminase levels were found to be increased significantly $(p<0.01)$ in alloxan treated diabetic rats incompare to normal control. The extract significantly $(\mathrm{p}<0.01)$ decreased the elevated alkaline phosphate, SGOT and SGPT in alloxan treated rats and the level significantly $(p<0.01)$ restored to normal after treatment. There was no significant difference between normal control and diabetic control. In diabetic animals the change in the levels of serum enzymes are directly related to changes in the metabolism in which the enzymes are involved. Many workers have reported increase in transaminase activities in the liver and serum of diabetic animals. The increased activity of transaminases which are active in the absence of insulin because of increased availability of aminoacids in diabetic are responsible for the increased gluconeogenesis and ketogenesis observed in diabetes [18]. In the present study the methanolic extract significantly decreased the enzyme activities. Hence the improvements noticed in the levels of the enzymes are as a consequence of improvement in carbohydrates, fats and protein metabolism. The lowering the value of SGOT and SGPT from higher value after the treatment also indicated the revival of insulin secretion. The increased level of ALP in diabetic rats found to be significantly reversed by the fraction. SGOT and SGPT levels are indicators of liver function, hence, restoration of normal levels indicate normal function of liver [19].

Table 5: Effect of methanolic extract of Grape seeds (MEGS) on ALP, SGOT and SGPT of control and experimental rats.

\begin{tabular}{|c|c|c|c|}
\hline Groups of Animals & ALP (IU/L) & SGOT (IU/L) & SGPT (IU/L) \\
\hline $\begin{array}{c}\text { Normal control }(0.5 \% \mathrm{w} / \mathrm{v} \\
\mathrm{CMC})\end{array}$ & $273.11 \pm 0.88$ & $32.106 \pm 0.80$ & $42.00 \pm 0.38$ \\
\hline $\begin{array}{c}\text { Alloxan control }(120 \mathrm{mg} / \\
\mathrm{kg})\end{array}$ & $544.29 \pm 0.56^{* *}$ & $63.19 \pm 0.52^{* *}$ & $79.11 \pm 0.92^{* *}$ \\
\hline $\begin{array}{c}\text { Alloxan+ MEGS (500 mg/ } \\
\mathrm{kg})\end{array}$ & $353.06 \pm 1.00^{* *}$ & $55.10 \pm 0.89^{* *}$ & $68.33 \pm 1.00^{* *}$ \\
\hline $\begin{array}{c}\text { MEGS (500 mg/kg) } \\
\text { Alloxan+Glibenclamide(5 } \\
\mathrm{mg} / \mathrm{kg})\end{array}$ & $283.22 \pm 1.13 \dagger$ & $38.01 \pm 2.88 \dagger$ & $41.25 \pm 0.76 \dagger$ \\
\hline
\end{tabular}

\section{Conclusion}

Hence the present study was focused on the antihyperglycemic and anti-inflammatory activities of methanolic extract of Grape seeds inalloxan induced diabetic rats. Different extract of the Grape seeds roots were subjected to phytochemical screening out of which methanolic extract was found to contain more number of phytochemical such as carbohydrates, proteins, alkaloids, tannins, saponins, flavonoids and coumarins. Hence, further study was done with methanolic seeds extract of Grape in animal's models to investigate the anti-diabetic and antiinflammatory activity. The rats were categorized into five groups. Rats in the group first treated normally and served as control. In group second, third and fifth rats diabetes was induced by giving alloxan. Among this, rats of group third treated with methanolic extract of the seeds of Grape. The fourth group without inducing diabetes treated with methanolic extract of seeds of Grape. The fifth group rats were treated with standard drug (glibenclamide). Alloxan, which is a chemical used for the induction of diabetes in animals, has been shown to damage pancreatic $ß$ cells by 
the liberation of oxygen radical. After the experiment regimen, the blood sample was taken for analyzing various biochemical parameters. The serum was used to determine the glucose, protein, lipid profile and liver marker enzymes like alkaline phosphatase, SGOT and SGPT. Insulin deficiency leads to various metabolic aberrations in the animal's viz., increased blood glucose, decreased protein content, increased lipid profile, ALP and transaminases.

Data represents mean \pm S.D. $(n=5) .,{ }^{*} p<0.05$ Significant as compared to Alloxan control., ${ }^{* *} \mathrm{p}<0.01$ Significant as compared to Alloxan control., ${ }^{* * *} \mathrm{p}<0.001$ Significant as compared to Alloxan control., $\uparrow$ :non significant compared to normal control

In the present study, an increase in serum glucose was noticed in diabetic rats, after the administration of the methanolic extract of Grape seeds there was a significant decrease of serum glucose level was obtained, this may due to the protection of $ß$-cells by roots extract which produce insulin that enhance glycogen synthase. Protein levels and lipid profile (cholesterol, HDL, LDL, VLDL and phospholipids) were increased in diabetic rats except HDL which was decreased. This may be due to excessive catabolism of protein and the released amino acids are used for gluconeogenesis and lipolysis in adipose tissue which give rise to hyperlipidemia respectively. The level of liver marker enzymes was also increased. The restoration of transaminases to their normal levels after the treatment also indicates revival of insulin secretion.

\section{References}

1. Amos AF, Mccarty DJ, Zimmet P (1997) The risingglobal burden of diabetes and its complication. Diabetic medicine 14(Suppl 5): 51-85.

2. Bajaj JS, Madan R Diabetes in tropics anddeveloping countries. IDF bulletin 995 38(2): 5-6.

3. David MN (1996) The pathophysiology of diabeticcomplication. How much dose the glucosehypotheses explain? Annals of Internal Medicine 174(1 Pt 2): 286-289.

4. Holman RR, Turner RC (1991) Oral agent and insulin inthe treatment of NIDDM In: Pickup J, Williams G (Eds.), Text book of Diabetes. Black well, Oxford, UK, 174:467-469.
5. Bodansky H (1989) The natural history of diabetes. Practical diabetes 6(1): 29.

6. Printz RL, Magnuson MA, Granner DK (1993) Mammalian glucokinase Annual Review of Nutrition 13: 463-496.

7. Bagchi D, Bagchi M, Stohs SJ, Ray SD, Sen CK, et al. (2002) Cellular protection with proanthocyanidins derived from grape seeds. Annals of New York Academy of Science 957: 260-270.

8. Sato M, Maulik G, Ray PS, Bagchi D, Das D (1999) Cardioprotective effects of grape seed proanthocyanidin against ischemic reperfusion injury. Journal of Molecular and Cellular Cardiology 31: 1289-1297.

9. Saito M, Hosoyama H, Ariga T, Kataoka S, Yamaji N, et al. (1998) Antiulcer activity of grape seed extract and procyanidins. Journal of Agricultural and Food Chemistry 46(4): 1460-1464.

10. Sethi PD (2004) Identification of drugs in formulations by TLC. $\left(2^{\text {nd }}\right.$ edn), CBS Publishers \& Distributors, New Delhi, India, p. 241.

11. Horborne JB (1998) Phytochemical methods. ( $3^{\text {rd }}$ edn), Spriger private limited, New Delhi, India, p. 60, 52.

12. Nandhakumar J, Sethumathi PP (2007) Anti-diabeticactivity of methanol leaf extract of Coctuspictus D. DON in alloxan induced diabetic rats. Journal of Health Science 53(6): 665-663.

13. Scoppala A, Montecchi FR, Mezinger G, Lala A (2001) Atherosclerosis. 156: $357-361$

14. Kraus-Friendmann N (1984) Hormonal regulation of hepatic gluconeogenesis. Physiology Review 64: 1706.

15. Austin MA, Hokanson JE (1994) Epidermiology of triglyceride, small dense low density lipoproteinand lipoprotein (a) as risk factor for coronary heartdisease. Medicine Clinics North America 78(1): 99-115.

16. Brown MS, Goldstein JL (1983) Lipoprotein receptor inthe liver Control signals for plasma cholesteroltraffic. The journals of Clinical Investigation 72(3): 743-747.

17. Luc G, Fruchart JC (1991) American Journals of Clinical Nutrition. 53 2065-2095.

18. Felig P, Marliss E, Ohman J, Cahil JF (1970) Plamaaminoacinos level in diabetic ketoacidosis. Diabetes 19: 727

19. Sumana G, Suryawashi SA (2001) Effect of vinkarosea extracts in treatment of alloxan diabetes in malealbino rats. Indian Journal of Express Biology 39(8): 748-759.

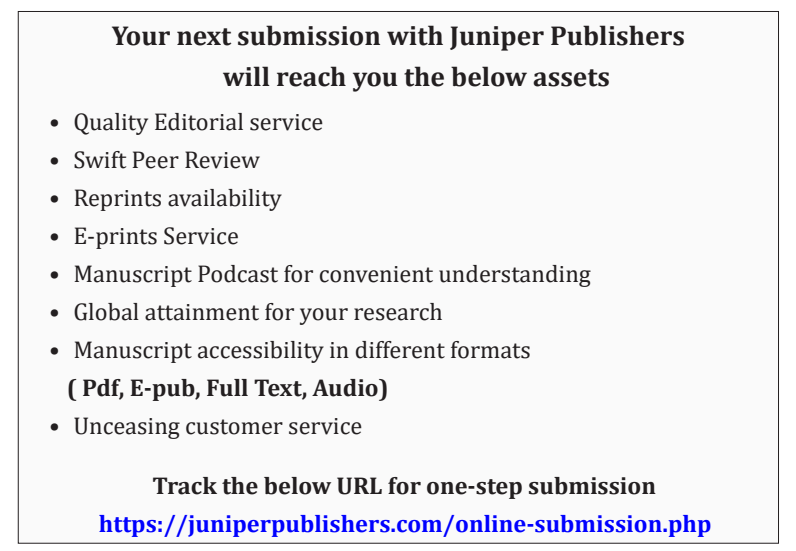


